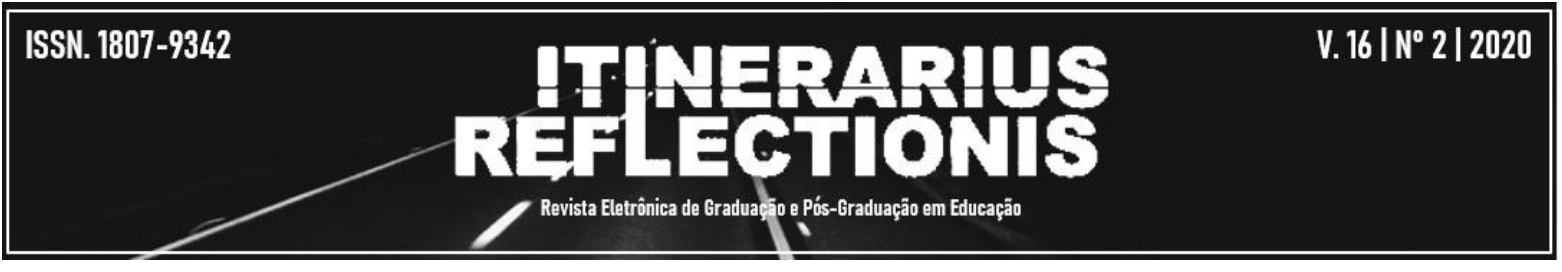

\title{
Esportes de combate na educação física escolar: a perspectiva dos alunos do ensino médio de uma escola do município de Jatai, Goiás
}

\author{
Douglas de Assis Teles Santos ${ }^{1}$ \\ Aline Martins Ferreira Silva ${ }^{2}$ \\ Sinara Moreira de Freitas Santos ${ }^{3}$ \\ Pollyana Freitas Silva Lima ${ }^{4}$ \\ Rízia Rocha Silva ${ }^{5}$ \\ Ricardo Borges Viana ${ }^{6}$ \\ Rafaela Gomes dos Santos ${ }^{7}$
}

Resumo. O objetivo desta pesquisa é verificar se há influência das lutas transmitidas pela mídia sobre a violência social na visão de alunos do ensino médio. A metodologia aplicada é caracterizada como quanti-qualitativa e exploratória, para a qual foi utilizado como instrumento de coleta de dados um questionário semiestruturado em que a análise de conteúdo foi adotada para sua interpretação. Para a discussão, os resultados apontaram as seguintes categorias de análises: influência da mídia; não há relações entre lutas e violência; identificação com os lutadores. Os participantes afirmaram acompanhar as lutas nos veículos de mídia e acreditam não haver relação entre as lutas, como esporte e a violência e finalmente, que eles se identificam com algum atleta que tenha sido campeão nas lutas em que participou em sua respectiva categoria. Pode-se concluir que há influência da mídia na percepção dos participantes sobre as lutas, mas eles sabem distinguir lutas de violência e ainda se identificam com lutadores.

Palavras chaves: Educação Física. mídia audiovisual. adolescente.

Fighting in school physical education: the perspective of the high school students of a school in the city of Jatai, Goiás.

Abstract. This research aims to verify if there is influence of the struggles transmitted by the media on social violence in the view of high school students. The applied methodology is characterized as a quantity and qualitative exploratory, for which a semi-structured questionnaire was used as a data collection tool in which the content analysis was adopted for its interpretation. For discussion, the results pointed to the following categories of analysis: media influence; there are no relations between fights and violence; identification with the fighters. The participants said they were following the struggles for the media and believe there is no relationship between the fights as sport and violence and, finally, they identify with some athlete who has been champion in the fights in which he participated in their respective category. One can conclude that there is influence of the media in the perception of the participants about the struggles, but that they know distinguish fights of violence and still, identify with the fighters

Keywords: Physical Education. audiovisual media. Adolescente.

\footnotetext{
${ }^{1}$ Doutorando em Ciências da Saúde pela Universidade Federal de Goiás. Professor na Universidade do Estado da Bahia, Campus X, Teixeira de Freitas. datsantos@uneb.br.

${ }^{2}$ Licenciada em Educação Física pela Universidade Federal de Goiás. alinemartinsferr@gmail.com.

${ }^{3}$ Bacharel em Educação Física pela Universidade Federal de Goiás. sinara_freitas@yahoo.com.br.

${ }^{4}$ Especialista em Morfofisiologia do Exercício pela Universidade Federal de Goiás. kapulleta@yahoo.com.br.

${ }^{5}$ Mestranda em Educação Física pela Universidade Federal do Triângulo Mineiro. riziarochasilva@gmail.com.

${ }^{6}$ Doutorando em Ciências da Saúde pela Universidade Federal de Goiás. vianaricardoborges@hotmail.com.

${ }^{7}$ Doutoranda em Educação Física pela Universidade Federal do Espírito Santos. Professora na Universidade do Estado da Bahia. rafagomes.edf@gmail.com.
} 


\section{INTRODUCÃO}

O movimentar faz parte da história desde o início da humanidade na busca do homem por território, alimento, poder, sobrevivência, etc. A luta se configura nesse processo, como um dos mais importantes elementos, para essas conquistas desde Pré-história, sendo praticada por razões de sobrevivência (DIAS JUNIOR, 2014).

Carneiro, Pícoli e Santos (2015), afirmam que a luta é uma prática corporal imprevisível com qual objetiva-se atingir um ou mais alvos, com o próprio corpo e/ou algum objeto para atacar ou se defender do(s) oponente(s), permitindo a possibilidade de os adversários atacarem ao mesmo tempo, sem a necessidade de seguir a ordem "um ataca, o outro defende", como nos esportes coletivos com bola (basquetebol, futebol etc.), ou em jogos como o xadrez, em que não acontece o ataque simultâneo; pelo contrário, cada um ataca ou defende a sua vez.

Com o passar dos anos foram atribuídas outras funções com a necessidade de fazer com que a circulação e apropriação das lutas chegassem em outras esferas da sociedade, atribuindo assim diferentes significados a ela, diferente do já conhecido. Sendo vistas atualmente como atividades de lazer, defesa pessoal e prática esportiva. A luta tem alcançado espaços como as academias de ginástica, clubes desportivos, escolas, entre outros ambientes, tornando-as suscetíveis a um processo de transformação e esportivização de sua prática (GONÇALVES; SILVA, 2013).

Sua repercussão midiática tem sido cada vez mais difundida, consolidando assim sua prática. Conquistando espaços na televisão e internet, a luta se moldou para chamar a atenção, criando novas regras, modalidades e práticas, gerando esportes como o MMA (Mixed Martial Arts) ou Artes Marciais Mistas que conquistou, e tem conquistado legião de consumidores do seu mercado. (DEMÉTRIO; OLIVEIRA, 2013).

Sobre o surgimento do The Ultimate Fighting Championhip (UFC), Souza-Junior, (2015) explica que UFC nasceu com o objetivo de descobrir qual era o melhor lutador do mundo, em 1993 onde o brasileiro Royce Gracie foi o campeão. Por poucas regras, no início, foi considerado um esporte polêmico e violento, inclusive chamado de "Vale Tudo". Sendo o MMA, um esporte de luta/combate desarmado, onde são permitidos golpes traumáticos, como socos, chutes e técnicas de solo, provindas de esportes como o Jiu-Jitsu, Muay-Thai, Boxe e Wrestling/greco-romana (BRETT, 2017). Segundo Neto (2016), através do UFC a 
popularidade do esporte só aumentou nos últimos 20 anos, trazendo grande apelo midiático, constituindo um novo mercado consumidor de eventos dessa natureza.

O MMA contemporâneo mudou drasticamente ao longo dos anos, adotando um conjunto unificado de regras que gerenciam as divisões de peso, arbitragem e julgamento (LOCKWOOD et al., 2018). Lutadores podem usar tanto golpear quanto agarrar para tentar vencer a luta por nocaute (KO), submissão ou decisão do juiz (FARES et al., 2018). Além disso, vários movimentos que podem causar danos significativos, foram banidos e medidas mais protetoras foram consideradas (SEIDENBERG, 2011). Como resultado, o MMA se tornou relativamente aceito, e desde então ganhou um rápido aumento de admiração em todo o mundo (SEIDENBERG, 2011; RAINEY, 2009).

A sua recente popularidade mundial (FARES et al., 2018) fez com que o UFC criasse o Hall da fama, como citado no site da organização:

O Hall da Fama do UFC é uma celebração dos pioneiros, dos inovadores e dos visionários. É uma celebração do DNA do UFC e das artes marciais mistas. O Hall da Fama do UFC é dividido em quatro categorias distintas ou "alas", comemorando conquistas e contribuições específicas. Estes servem como diferenciais e permitem ao UFC posicionar os membros do Hall da Fama em seus contextos históricos apropriados (UFC, 2019).

O MMA continua sendo um esporte violento, com um risco de lesão maior do que outros esportes de combate, como o boxe profissional e a luta livre (LUNDBERG, 1996; NGAI et al., 2009; KARPMAN et al., 2016; SCOGGING, 2010; LYSTAD et al., 2014; McCLAIN et al., 2014). "A violência não é fenômeno isolado, pois resulta das interações sociais e se manifesta de forma especifica em cada cultura, e de acordo com o conjunto de normas e valores que orientamos indivíduos de uma sociedade" (PAREDE et. al., 2006, p. 06). Esta surge na realidade social como ameaça constante progredindo a cada dia, calando as pessoas, mudando seus comportamentos como tira- lós da posição de humanidade e leva-los a condição de objeto de sujeito racional pensante e comunicativo para passivo, irracional e mudo. Parede et al. (2006) sugere que a violência atual resulta da alteração do equilíbrio entre os modos de violência, decorrentes da transformação dos meios de controle social, das formas como os membros da nossa sociedade se relacionam entre si e da competitividade excessiva.

Nascimento e Correia (2012), consideram o MMA um esporte que pode diretamente estar ligado à questão da violência, pode-se levar o público a um exagero pela tal prática com as emissões televisivas ou diminuir, caracterizando-o como todo esporte, com 
suas regras, treinamentos e competições, deixando de lado o confronto físico que há entre os lutadores no octógono. Para MacDonald et al. (2017) É preciso compreender as questões legítimas que envolvem a valorização subcultural da violência e os males sociais mais amplos dentro do MMA, incluindo a normalização intergeracional da violência e/ou o transbordamento consciente ou inconsciente da violência nos contextos cotidianos.

Segundo Miranda Filho e Santos (2014) com os meios de comunicações, a realidade passa a ser não só vivida como transmitida, através de elementos que possibilitam reapresentar essa realidade. Assim, este trabalho tem por objetivo verificar se há influência dos esportes de combate transmitidos em mídia sobre a violência social no contexto dos alunos do ensino médio.

\section{METODOLOGIA}

Este estudo utilizou-se da pesquisa quanti-qualitativa e exploratória. Foi desenvolvido em uma escola da rede estadual no município de Jataí, Goiás. Foram selecionados aleatoriamente 10 participantes de cada série regular do ensino médio $\left(1^{\circ}, 2^{\circ}\right.$ e $3^{\circ}$ ano), assim a amostra iniciou-se com 30 participantes. Para a coleta de dados foi elaborado um questionário semiestruturado composto por 17 questões abertas e fechadas.

Foi adotado como critério de inclusão os participantes estarem matriculados, frequentando as aulas regularmente e estarem presentes no dia da entrega do instrumento. Este deveria ser respondido em casa e devolvido no dia posterior. Desta forma, apenas 15 participantes ( 6 alunos do $1^{\circ}$ ano, 5 alunos do $2^{\circ}$ ano e 4 alunos do $3^{\circ}$ ano, de ambos os sexos e a faixa etária entre 15 a 21 anos) devolveram o questionário preenchido. O único critério de exclusão adotado foi a possível recusa em participar do estudo, seja do voluntário ou dos pais, ressaltando que não houve nenhuma exclusão. Os participantes deram seu consentimento para a participação na pesquisa através do Termo de Assentimento do Menor e a autorização dos pais foi obtida através do Termo de Consentimento Livre e Esclarecido. Todos os procedimentos obedeceram aos princípios descritos na Declaração de Helsinque.

Para análise de dados quantitativos, foram utilizados procedimentos de estatística descritiva, com os resultados expressos em valores absolutos e relativos (percentual). Para análise de dados qualitativos os participantes receberam nomes fictícios com as letras do alfabeto de "A" a "O" e foi utilizado a técnica de análise de conteúdo para a compreensão dos 
dados, caracterizada por analisar respostas e agrupa-las em categorias como afirma BARDIN (1977). Foram identificadas três categorias de análises que serão explanadas a seguir.

\section{RESULTADOS E DISCUSSÃO}

Após a leitura foram atribuídos códigos de acordo com a semelhança das respostas formando três categorias de análise. As categorias são: influência da mídia (IM); relações lutas e violência (RLV); e identificação com as lutas (IL).

\subsection{Influência da mídia}

Através das respostas apontadas, podemos observar a percepção sobre as lutas explícitas por influência da mídia. Na questão relacionada ao acompanhamento das lutas pela televisão, $40 \%$ (6) dos participantes "acompanham", outros 33,33\% (5) responderam "às vezes" e 26,66\% (4) relataram "não acompanhar". O fato de a maioria acompanhar as lutas pela televisão pode estar influenciando a formação da opinião de jovens. Quando questionados se gostavam de acompanhar as lutas a maioria relatou "sim" (73,33\%).

Torezani (2012, p.09) afirma em relação a influência da mídia “O mundo da mídia e o mundo imaginado. Pelo que é real pode reapresentar-se através de um meio com recortes e formatos e, ao ter contato com este reenquadramento do real, surge para cada pessoa um mundo".

Além disso, as preocupações políticas e morais em torno do MMA estão ligadas a questões comportamentais potencialmente reais e legítimas, à medida que a pesquisa psicológica debate o vínculo entre assistir a esportes de combate (e "meios violentos" em geral) e atitudes e comportamentos agressivos (BRETT, 2017).

Conforme Martino (2009) apud Torezani (2012), ver televisão desde a infância estrutura esquemas mentais de acordo com interpretações dadas pela mídia, por isso a teoria da cultivação se ocupa dos indicadores culturais que regulam a percepção da realidade e ação das pessoas.

Quando perguntado qual tipo de lutas eles assistiam, boa parte $(66,66 \%)$ relatou assistirem MMA e o UFC. Interrogados se assistiam as lutas de MMA transmitidas pela televisão 66,66\% responderam "sim" ou "às vezes" $(33,33 \%)$. Os sujeitos não conseguem distinguir UFC de MMA. Segundo Torezani (2012, p. 1): 
A Ultimate Fighting Championship, mais conhecida como UFC, é uma organização de artes marcias mistas (mixed martial arts - MMA), em que os lutadores conhecem e utilizam técnicas de diferentes esportes, como boxe, jiu-jitsu, boxe tailandês (muay thai), karatê, boxe chinês, judô, luta livre olímpica e wrestling.

\subsection{Não há relações entre lutas e violência}

Questionados se acreditavam que as lutas transmitidas pela televisão eram violentas, 8 participantes $(53,33 \%)$ não consideraram como sendo violentas, percebendo a classificação como "esporte" e que os lutadores são treinados para tal. É interessante destacar a resposta de dois participantes "A" e "B". Sujeito "A" respondeu da seguinte forma: "Não! No futebol e outros esportes acontecem às mesmas lesões ou até piores das que acontecem no MMA. Quem decide ser lutador sabe que está em perigo de se machucar". Relevante esta fala onde ele associa um esporte que envolve lutas com um esporte que não envolve, acabando demostrando mais ações violentas do que o próprio MMA.

Segundo Elmagd (2016) em estudo realizado sobre lesões frequentes no esporte as taxas de lesões são mais altas para atletas que participam de esportes de contato, mas as lesões mais graves estão associadas a atividades individuais.

Pode se dizer que MMA não é o único esporte causador de lesões, outros esportes também podem causar lesões. Aluno "B" disse: "Não porque a luta é um esporte que consiste no contato físico". Há compressão desse sujeito enquanto luta sendo esporte e assim propenso a contatos físicos à existência do contato físico no esporte.

Outros $(n=7,46,66 \%)$ participantes consideram que os golpes são violentos. Destacam-se três respostas. Os sujeitos "C", "D" e "E". O sujeito "C" afirma: "depende do ponto de vista, fora dos ringues, eu acho violência". Ele considera que como é dentro do ringue seja normal, mas fora, considera como atos violência. Sujeito "D" comenta: "sim é um esporte muito violento, mas apesar de tudo é só um esporte e fora do ringue não rola nada". Ele considera próprio do esporte ser violento, entende que fora do ringue é diferente e no meio social eles não agem como fazem nos ringues. Sujeito "E” relata: "Sim. Pois, algumas das vezes eles provocam o outro para brigar. Também eles machucam de mais uns aos outros, mesmo não querendo." Esse sujeito acredita que a provocação acaba chamando para brigas, associa com violência ocorrida nos espaços sociais, iniciadas por provocações.

Os atos de violência permissivos no esporte geram dilemas éticos onde espera-se que na sociedade tais atos sejam evitados, mas são estimulados por diversos esportes e 
transmitidos pela mídia. Além de que este tipo de violência não apresenta nenhum objetivo em si, apenas o entretenimento e diversão (GREENWELL, 2015).

Debatido se consideram o MMA com atos de violência ou se consideravam normal, a maioria relatou "normal" apenas um sujeito considerou mais violenta em relação às outras modalidades de lutas.

Interrogados como reagiam ao verem um lutador chutando ou socando o adversário, 33,33\% ( $\mathrm{n}=5)$, consideram "normais", 13,33\% $(\mathrm{n}=2)$, relataram que tapam o rosto quando veem, $26,66 \%(n=4)$ consideram a cena muito forte, $6,66 \%(n=1)$, relata ser "horrível" e 6,66\% ( $\mathrm{n}=1)$ afirma que ao ver sente adrenalina. Os outros 13,33\% (n=2) relatam que é a mesma sensação de ver um gol no jogo de futebol.

Greenwell (2015) afirma que os aspectos violentos apresentados no esporte podem ser excitantes e fornecer imagens poderosas para o marketing, não sendo um fenômeno exclusivo do MMA, mas que outros esportes como hóquei no gelo, basquete, beisebol e colisões automobilísticas, tendem a destacar os shows esportivos, gerando assim maior mídia, se tornando viral.

Questionados se acreditam que as atitudes dos lutadores podem influenciar a violência nas ruas, 60\% ( $\mathrm{n}=9$ ) responderam "não", consideram que as pessoas se conscientizam que é um esporte, sujeito "B" relata: "não porque tem muita diferença de luta e briga", 26,66\% ( $\mathrm{n}=4)$, relaram "talvez", "agem por impulso", o sujeito "L”, afirma: "Talvez, mas cada pessoa reage de uma forma, umas se influenciam outras como eu não vê problema, como se fosse um jogo de futebol, assisti porque gosta" 26,66\% (n = 4) "sim", a reposta do sujeito "E": "Sim. Pois eles acabam querendo ser igual e não ver suas atitudes no ringue". A maioria dos participantes questionados não acredita que tal atitude pode influenciar o telespectador e/ou admirador do esporte a reproduzir tal prática violenta nas ruas.

Questionados se acreditavam se as lutas transmitidas pela televisão são violentas, $53,33 \%(\mathrm{n}=8)$ não consideram como sendo violentas, percebendo a classificação deste como esporte e que os lutadores são treinados para tal. É interessante destacar a resposta de dois sujeitos "A" e o "B". Sujeito "A" respondeu da seguinte forma: "Não! No futebol e outros esportes acontecem às mesmas lesões ou até piores das que acontecem no MMA. Quem decide ser lutador sabe que está em perigo de se machucar". É relevante nesta fala ele conseguir associar um esporte que envolve lutas com um esporte que não envolve, que demostra mais ações violentas do que o próprio MMA. Aluno "B" relata: "Não porque a luta é um esporte que consiste no contato físico". Há compressão desse sujeito enquanto luta 
sendo esporte e assim propenso a contatos físicos. Torezani (2012, p.10) traz em seu texto relato de Vitor Belfort em uma entrevista em jornal onde ele expressa sua opinião sobre a questão da violência:

\begin{abstract}
O lutador Vitor Belfort indica que o futebol é mais violento que o MMA, já que é o esporte "favorito" dos brasileiros. Para Belfort, o MMA é "um esporte menos político e corrupto que o futebol porque é uma competição homem a homem, um ganha e o outro perde. O jogador fica barrigudo, não joga nada, mas também não se aposenta porque está ganhando 1 milhão por mês"13. Ainda afirma que, comparado ao hockey e ao ciclismo, o MMA não é o esporte mais violento do mundo. Abre-se uma nova discussão sobre violência agora ligada ao esporte "favorito" dos brasileiros. Pouco se trata através dos meios de comunicação, da violência que há dentro do campo e fora dele com os torcedores quanto à violência do futebol, aparecendo brigas de torcidas organizadas, mas sempre de maneira pontual. Na comparação, a arena de conflito do octógono é o templo da violência e o gramado, não. $\mathrm{Na}$ verdade, ambos os espaços geram violência pelo contato físico que predispõem.
\end{abstract}

Alvarez (2012, p. 13) relata sobre a questão da violência no octógono como ela pode ser entendida:

Se tomarmos as lutas que acontecem no espaço delimitado para elas, se encaramos o octógono como uma espécie de palco sacralizado, a violência que lá ocorre não pode ser encarada como uma simples briga de rua, mas sim como uma violência simbólica, onde vida e morte são colocadas não como negação uma da outra, mas como complementos indissociáveis.

Indagados se consideram que a lutas transmitidas pela televisão tem alguma relação com essas vistas entre alunos dentro e fora da escola, 66,66\% (n = 10) "não", consideram que os alunos não reproduzem tudo que "vê na televisão", "não há relação com violência", as "brigas" tem outros motivadores não relacionados às lutas, a violência acaba sendo ocasionada por relacionamento como "namoro" do que pela influência da mídia, e $33,33 \%(\mathrm{n}=5)$ "sim", porque querem reproduzir os gestos dos lutadores.

Questionando a opinião deles em relação à violência, eles consideraram: "deveria ser banida do mundo"; "sem fundamento"; "atitude de ofender alguém"; "covardia", "crueldade"; "criminalidade em excesso"; "algo que precisa de atenção"; "falta de paciência"; "atitudes"; "atos"; "comportamento que causa consequências idiotas". Sujeito "F" define: "contato físico desproporcional". Sujeito "A" descreve: "A violência e inevitável, estamos sujeitos a sofrer violência até mesmo dentro de nossas casas". Ele descreve todos nós estamos sujeitos a sofrer violência e qualquer local. "L" conceitua: "Violência, com belas palavras não sei dizer, mas é um ato de quando alguém agiu sem motivo ou bate por prazer 
de ser forte ou mostrar que pode sem ao menos o outro ter oportunidade de defesa". Ela considera como ato sem motivo praticado por prazer e onde as pessoas usam força excessiva em individuo não dando oportunidade de defesa.

\subsection{Identificação com os lutadores}

Perguntados com qual lutador se identificavam, apenas um sujeito relatou não se identificar com nenhum. Entre os lutadores citados estão Anderson Silva 33,33\% ( $n=5)$, Vitor Belfort 20\% ( $\mathrm{n}=3$ ) e os outros citados são: Bruce Lee, Cane (WWE), José Aldo, Júnior Cigano, John Ciena e Minotauro. A maioria dos lutadores citados são brasileiros e campeões em suas respectivas categorias, são mais conhecidos e divulgados através da mídia por desempenharem também outros papeis importantes, no universo desse esporte e por suas histórias de vida e superação, etc.

Segundo Torezani (2012, p.3): "Na disputa de pesos pesados, ganhou o brasileiro Junior Cigano; esta exibição teve comentários do lutador Vitor Belfort, com narração de Galvão Bueno.” Podemos observar que para esses eventos estão sempre envolvidas pessoas as quais fazem parte do esporte de uma forma geral no caso do narrador de futebol, voleibol, corridas automobilísticas, etc. Envolvidos também atletas de renome em sua categoria para comentar sobre a (luta), sobre o lutador, fazendo comentários em torno deste título que está sendo disputado e até mesmo contando sobre a história do cinturão em disputa, chamando atenção do público para que volte os olhos para esse esporte e para os lutadores.

Quando questionados se poderiam dizer quem havia ganhado a última luta de MMA transmitida pela televisão, $60 \%(\mathrm{n}=9)$ relataram não ter acompanhado, $20 \%(\mathrm{n}=3)$ disseram não se lembrar, $13,33 \%(\mathrm{n}=2)$ não assistiram e 6,66\% $(\mathrm{n}=1)$ afirmou ter sido José Aldo.

Questionados se já se assustaram acompanhando essas lutas pela televisão, 46,66\% ( $\mathrm{n}=7)$ sujeitos relataram "não", $40 \%(\mathrm{n}=6)$ relataram que "sim", quando viram lutadores sofrerem lesões graves, 6,66\% $(\mathrm{n}=1)$ "quase todas" $6,66 \%(\mathrm{n}=1)$ "às vezes". Destaque para três respostas: Sujeito "A” diz: "sim! Já vi lesões muito graves e já sofri lesões graves." Sujeito "C" relata: "sim. Vi um cara morrer devido a uma pancada estrema no pescoço." Sujeito "F" respondeu: "sim, quando um lutador ao chutar seu adversário quebrou a perna." É perceptível o susto que levaram quando acompanhava a luta está relacionado a um golpe que causou uma lesão ou que foi fatal. 
Brett (2017, p.13) citando um historiador do boxe Elliot Gorn diz que o MMA "É toda a estética da violência que é realmente perturbadora [...] o que é surpreendente para mim é a conexão entre televisão e pay-per-view e lucro. Isso é caos para a venda". Ele acaba trazendo as questões da quais muito dos sujeitos responderam próximas de sua afirmação.

Questionados sobre o que chamava mais atenção deles no comportamento do lutador no ringue, 33,33\% ( $\mathrm{n}=5)$, responderam como eles se "movimentam no octógono", "estratégias dos golpes", o restante ficou entre "velocidade", "força", "violência", "a resistência", "vontade de vencer e lutar", "a agilidade" e "agressividade." O relato de três sujeitos: "B": "respeito pelo adversário"; Sujeito "G” que vai ao contrário do sujeito citado acima "O jeito de ele bater eu gosto quando ele é bastante agressivo e vai pra cima sem dó e sem piedade"; Sujeito "H" "Que eles mudam a sua personalidade bem diferente de quando estão fora".

Interrogados se gostariam de praticar alguma arte marcial, apenas um dos sujeitos relatou "não". Nas respostas afirmativas á maioria relatou que gostariam de praticar por trazer "benefícios ao corpo", porque considera "bonita" e para "defesa". Sujeito "B" relata: "sim porque eu acho legal o que as lutas ensinam". Nota-se que o nível de percepção de artes marciais vai além do que pode imaginar foram respostas consideráveis o uso da luta pra se "defender" em "benefício da saúde", em conformidade com a resposta do sujeito "B" que consegue atribuir as lutas algo mais á ensinar, do que apenas golpes, há uma filosofia inserida.

Hammami, (2018, p.74) faz algumas considerações porque determinadas pessoas buscam á pratica das artes marciais:

A popularidade desses esportes está florescendo em diferentes idades, por uma
variedade de razões, tais como manter habilidades físicas, melhorar o equilíbrio,
flexibilidade e força, e obter benefícios para a saúde. As artes marciais também
podem ser consideradas como uma excelente ferramenta terapêutica que desenvolve
concentração, socialização, autoestima, aprimora a disciplina e autodefesa na
população mais jovem.

Se pensarmos em relação ao que o autor diz baseia-se nas respostas dadas pelos sujeitos dos questionários eles respondem de acordo com o autor vem a afirmar.

Indagados se acreditavam que as lutas traziam alguma influência para o nosso convívio social, a maioria disse "não", outros consideraram "depende de cada pessoa". Interessante ressaltar a fala de dois sujeitos " $\mathbf{A}$ " $\mathrm{e}$ " $\mathbf{B}$ '. Onde " $\mathbf{A}$ " relata: "Não crianças que são colocadas nas artes marciais crescem com disciplina respeito. As lutas influenciam em boa disciplina". A resposta desse aluno acaba indo ao contrário dos outros $40 \%(\mathrm{n}=6)$ relatos que consideram que as lutas sejam má influência para as crianças. O sujeito "B" afirma: "Não, 
porque se a pessoa respeita ela percebe a diferença com a realidade", essa resposta se aproxima daquelas relatadas, que depende de cada indivíduo.

Interrogados qual compreensão deles sobre lutas, 53,33\% $(\mathrm{n}=8)$ conceituam como "esporte". Entre outras opiniões temos: "é profissional ato de defesa", "é uma descontração para o dia-dia", "agora é um esporte legalizado", "ato de praticar exercício", "horrível". Resposta de sujeitos "A", "B"," F"," I". Sujeito "A"; "é esporte como todos os outros onde há dignidade e muitas outras qualidades que não se encontra em outros esportes". Ele relata que é um esporte e merece ser respeitado como os outros e que nele há qualidade. "B”, "é um esporte praticado apenas nas condições corretas de prática”. Sujeito "F", “depende da ocasião se estiver em um ringue apropriado com regras, se trata de esporte, mas se for uma coisa por intrigas, banal desproporcional". Podemos identificar as respostas estão associando lutas ao esporte. Sujeito "I" relata: "Lutas só dentro do ringue, fora só defesa". Ele define que o local indica um sentido para o uso das lutas seja dentro ou fora do ringue ela pode ter uma conotação ou sentindo diferente. Rissi (2010, p.17) conceitua lutas e artes marciais que:

As lutas são práticas que possuem embates corporais. Já as artes marciais significam métodos de guerra ou conjuntos de preceitos que um guerreiro utiliza, principalmente visto em filmes de guerra. As artes marciais são uma filosofia que se baseia em preceitos éticos, estéticos e morais no qual normalmente foram utilizadas como legítima defesa.

São limitações do presente estudo: a utilização de questionários e consequentemente a baixa devolução do mesmo pelos participantes; os resultados não refletem a opinião de todos os alunos do ensino médio da escola investigada, apenas de uma amostra selecionada aleatoriamente; os esportes de combate abordados foram apenas o MMA.

\section{CONSIDERAÇÕES FINAIS}

Os resultados do estudo demonstraram que o interesse pelas lutas tem crescido e as pessoas não á generalizam como a maior causa da violência. O público tem se tornado cada vez mais crítico em relação essas lutas transmitidas pela mídia. Até se identificam com algum ídolo, mais, isso não os aliena não influenciando em suas respostas, expressam sua opinião sobre o esporte e sua relação com o social. 
Os sujeitos participantes demonstraram amadurecimento, quando questionados se acreditam na influência das lutas na violência. A maioria relatou não acreditar, pois cada indivíduo tem uma maneira de perceber, nem sempre reproduzem o que assistem. Consideram a luta violenta, mas, acreditam que as lutas não influenciam na violência social. Observam que tem algo a mais para ser ensinado nas lutas não apenas golpes trazendo benefícios para saúde, corpo, mente, podendo ser utilizada para defesa.

Por fim, percebemos não haver influência dos esportes de combate, transmitidos nas mídias, no contexto social desses estudantes. Sugere-se a realização de novas pesquisas para investigarem quais os possíveis fatores influenciadores da violência, no contexto social, desses alunos. Além disso, poderia ser utilizado os esportes de combate como instrumento contra a violência, direcionando os alunos à prática do esporte.

\section{REFERÊNCIAS}

ALVAREZ, Fábio de Lima; MARQUES, José Carlos. MMA e a busca de identidade em uma cultura em vias de Globalização. In: Anais da INTERCOM. XXXV Congresso de Ciências da Comunicação, Fortaleza - CE, set. 2012.

BRETT, Gordon. Reframing the 'Violence' of Mixed Martial Arts: The 'Art' of the fight. Poetics. n.62, p. 15-28, 2017.

BARDIN, Laurence. Análise de Conteúdo. São Paulo. Edições 70. Persona. 1977.

CARNEIRO, Felipe; PÍCOLI, Carlos; SANTOS, Wagner. Fundamentos ontológicos e epistemológicos das lutas corporais. Pensar a prática. v. 18, n. 3, p. 725-738, 2015.

DEMÉTRIO, N; OLIVEIRA, C. M. A influência da mídia no esporte: um olhar a partir do MMA. Revista Caminhos, On-line, "Saúde”. Rio do Sul, a. 4 n. 7, p. 41-54, 2013.

DIAS JUNIOR, Elson Moura. Das lutas populares às lutas nas olimpíadas e Metodologia do ensino das lutas: uma proposição critico-superadora, 2014.

ELMAGD, M. A. Common Sports Injuries. International Journal of Physical Education, Sports and Health. n. 3, v. 5, p. 142-148, 2016.

FARES, M. Y; FARES, J; FARES, Y; ABBOUD, J. A. Musculoskeletal and head injuries in the Ultimate Fighting Championship (UFC). The Physician and Sportsmedicine. v. 47, n. 2, p. 205-211, 2019.

GONÇALVES, A. V. L; SILVA, M. R. S. Artes marciais e lutas: Uma análise da produção de saberes no campo discursivo da Educação física brasileira Revista Brasileira de Ciências do Esporte. Florianópolis, v. 35, n. 3, p. 657-671, 2013.

GREENWELL, T. C; THORN, D; SIMMONS, J. Is violence used to promote Mixed Martial Arts? International Journal of Sports Marketing \& Sponsorship. v.16, n.4, p. 10-21, 2015.

HAMMAMI, N. et al. Combat sport injuries profile: A review. Science \& Sports. n. 33, p. 73-79, 2018. 
KARPMAN, S; REID, P; PHILLIPS, L; QIN, Z; GROSS, D. P. Combative sports injuries: na Edmonton retrospective. Clin J Sport Med. v. 26, n. 4, p. 332-334, 2016.

LOCKWOOD, J; FRAPE, L; LIN, S; ACKERY, A. Traumatic Brain injuries in mixed martial arts: A systematic review. Trauma. v. 20, n. 4, p. 245-254, 2018.

LUNDBERG, G. D. Blunt force violence in America-shades of gray or red: ultimate/extreme fighting. JAMA. v. 275, n. 21, p. 1684-1685, 1996.

LYSTAD, R. P; GREGORY, K; WILSON, J. The epidemiology of injuries in mixed martial arts: a systematic review and meta-analysis. Orthop J Sports Med. v. 2, n. 1, p. 1-10, 2014.

MACDONALD, K. E; LAMONT, M; JENKINS, J. M. Ultimate Fighting Championship Fans: Foundations of Subcultural Stratification. Leisure Sciences. p. 2-19. 2017.

McCLAIN, R; WASSERMEN, J; MAYFIELD, C; BERRY, A. C; GRENIER, G; SUMINSKI, R. R; Injury profile of mixed martial arts competitors. Clin J Sport Med. v. 24, n. 6, p. 497-501, 2014.

MIRANDA FILHO, V. F; SANTOS, I. S. MÍDIA, MERCADORIZAÇÃO ESPORTIVA E O MOVIMENTO DE POPULARIZAÇÃO DO MMA. Pensar a prática. v. 17, n. 3, p. 865877, jul./set. 2014.

NASCIMENTO, S; CORREIA, D. Por que tanta gente está de olho em Anderson Silva. Veja. São Paulo, ano 45, n. 11. São Paulo, 14 de mar. 2012.

NETO, Álvaro; GARCIA, Roberto; VOTRE, Sebastião. Artes marciais mistas: luta por afirmação e mercado da luta. Revista Brasileira Ciência do Esporte. n.38, v.4, p. 407-413, 2016.

NGAI, K, M; LEVY, F; HSU, E. B. Injury trends in sanctioned mixed martial arts competition: a 5-year review from 2002 to 2007. Br J Sports Med. v. 42, n. 8, p. 686-689, 2009.

SCOGGING J. F. 3rd; BRUSOVANIK, G; PI, M; IZUKA, B; TOKUMURA, S; SCUDERI, G. Assessment of injuries sustained in mixed martial arts competition. Am J Orthop. v. 39, n. 5, p. 247-251, 2010.

SEIDENBERG, P. H. Mixed martial arts: injury patterns and issues for the ringside physician. Curr Sports Med Rep. v. 10, p. 147-150, 2011.

RAINEY, L. C. Determining the prevalence and assessing the severity of injuries in mixed martial arts athletes. N Am J Sports Phys Ther. v. 4, p. 190, 2009.

TOREZANI, Juliana Nascimento. A transmissão dos eventos do UFC pela Rede Globo: Uma análise pelas Teorias de Construção Social. In: Anais INYERCOM, XIV Congresso de Ciências da Comunicação na Região Nordeste, Recife - PE, junho. 2012.

UFC. Ultimate Figther Championship. The Sport: UFC Hall of Fame. UFC, 2019. Disponivel em: https://www.ufc.com.br/ufc-hall-fame. Acesso em: 29 de julho de 2019. 